\title{
MENSURAÇÃO DO DESLOCAMENTO DA DURA-MÁTER NA PUNÇÃO SUBOCCIPITAL MEDIANA
}

SANDRO L. ROSSITTI ** - IGOR R. THOMAZ * - ROQUE J. BALBO **

RESUMO - Estudo da anatomia dinâmica da punção suboccipital mediana da cisterna magna em cadáveres frescos. O deslocamento («tenda») da dura-máter foi observado em todas as punções $(\mathrm{n}=30)$, medindo $3,12(2,0-4,2) \mathrm{mm}$.

Measurement of the dural mobility («tenting») during median suboccipital puncture.

SUMMARY - Report of a study of the dynamic anatomy of the median suboccipittal puncture of the cisterna magna cerebellomedullaris, carried out on fresh cadlawerss. IDirect inspection of the internal surface of the dura imatter (IDMI)) att the conanioceenviicall neegiom wwas possible by removing the calwarium and brain (secciomedl at the upper cervical cord), during routine necropsies. Disslocation off the IDWI oween the needlle tip preceding dural penetratiiom ((sco-called

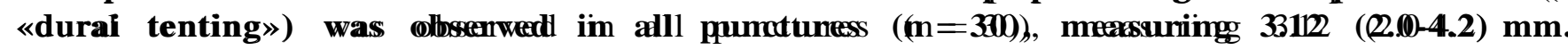

A natureza complexa de muitas afecções do sistema nervoso central torna a punção da cisterna magna ( $C M$ ) método diagnóstico útil para a coleta de líquido cefalorraqueano ( $L$ C R ) e, a despeito do desenvolvimento da tomografia axial computadorizada e da ressonância magnética nuclear, para alguns procedimentos neurorradiológicos. No presente estudo são abordados alguns aspectos da anatomia dinâmica da punção suboccipital mediana ( PSOM) da CM

\section{TÉCNICA}

A despeito de ser amplamente conhecida e praticada em nosso meio, julgamos necessário incluir breve descrição da técnica de PSOM. O paciente deve ser posicionado em decúbito lateral (com a cabeça apoiada, mantendo o eixo crânio-caudal da coluna cervical paralelo ao plano de apoio do paciente) ou em posição sentada, com leve flexão cervical (mais acentuada superiormente, aproximando o mento do terço médio do pescoço) o que permite maior afastamento entre a escama occipital e o atlas. Após antissepsia (e tricotomia da nuca, se necessário) e infiltração da pele com solução anestésica local, uma agulha (com mandril, em geral de $80 \times 0,8 \mathrm{~mm}$ ) é inserida na linha média, entre a protuberância occipital externa e o processo espinhoso do axis, e dirigida anterior e superiormente em direção à glabeia. A penetração do espaço cisternal dá-se em média a 4 ou $6 \mathrm{~cm}$ de profundidade, sendo precedida de sensação táctil característica ao se atravessar a membrana atlanto-occipital e a dura-máter (DM); essa sensação nem sempre ocorre e recomenda-se retirar o mandril a cada pequeno avanço da agulha, uma vez atingidos os planos mais profundos. Se a agulha atingir a base do occipital, deve ser recuada até a pele e reinserida com inclinação levemente inferior. Após a manometria, coleta de $L \mathbf{C R}$ ou injeção de contraste, o mandril é recolocado e a agulha retirada, aplicando-se a seguir compressão local por alguns minutos.

As contra-indicações para a PSOM são: infecção local, septicemia, anormalidade óssea ou artrodese occipitocervical, suspeita de lesão expansiva da fossa posterior e malformação de Arnold-Chiari.

Departamento de Neuro-Psiquiatria da Faculdade de Ciências Médicas da Pontificia Universidade Católica de Campinas: * Médico Residente; ** Professor Adjunto.

Dr. Roque J. Balbo - Departamento de Neurocirurgia, Hospital Vera Cruz - Avenida Andrade Neves 402 - 13020 Campinas SP - Brasil. 
As complicações em potencial, respeitadas as contra-indicações mencionadas, incluem lesão direta da medula oblonga pela agulha e lesão vascular (da arteria cerebelar posterior inferior ou PICA, de um vaso com trajeto anômalo ou de veias da DM) que pode levar a hemorragia subaracnóidea, hematoma e infarto cerebelar ou bulbar.

\section{MATERIAL E MÉTODOS}

Em três cadáveres frescos (adultos, examinados menos de 24 horas após o óbito, na sala de necropsias do Hospital e Maternidade Celso Pierro, FCM-PUCCAMP), foram realizadas 30 punções cisternais medianías (PSOM) pela técnica convencional. Empregamos em todas as punções agulhas de $80 \times 0,8 \mathrm{~mm}$, com mandril, de bisel agudo e regular. A remoção da calvaría e do encéfalo (seccionado ao nivel da medula cervical alta, em Cl ou C2), permitiu visão direta da DM na junção crânio-cervical durante as punções. O deslocamento da DM foi observado até o momento de sua penetração. Uma vez perfurada a DM, esta era levada de volta a sua posição inicial, mantendo-se fixa a agulha. Medimos então a extensão intradural da agulha.

\section{RES ULT A D OS}

Em 30 punções cisternais medianas (PSOM), observamos o deslocamento da DM (dita ««tenda durai») em todos os casos, medindo de 2,0 a 4,2 mm, em média 3,12,mm (Fig. 1).

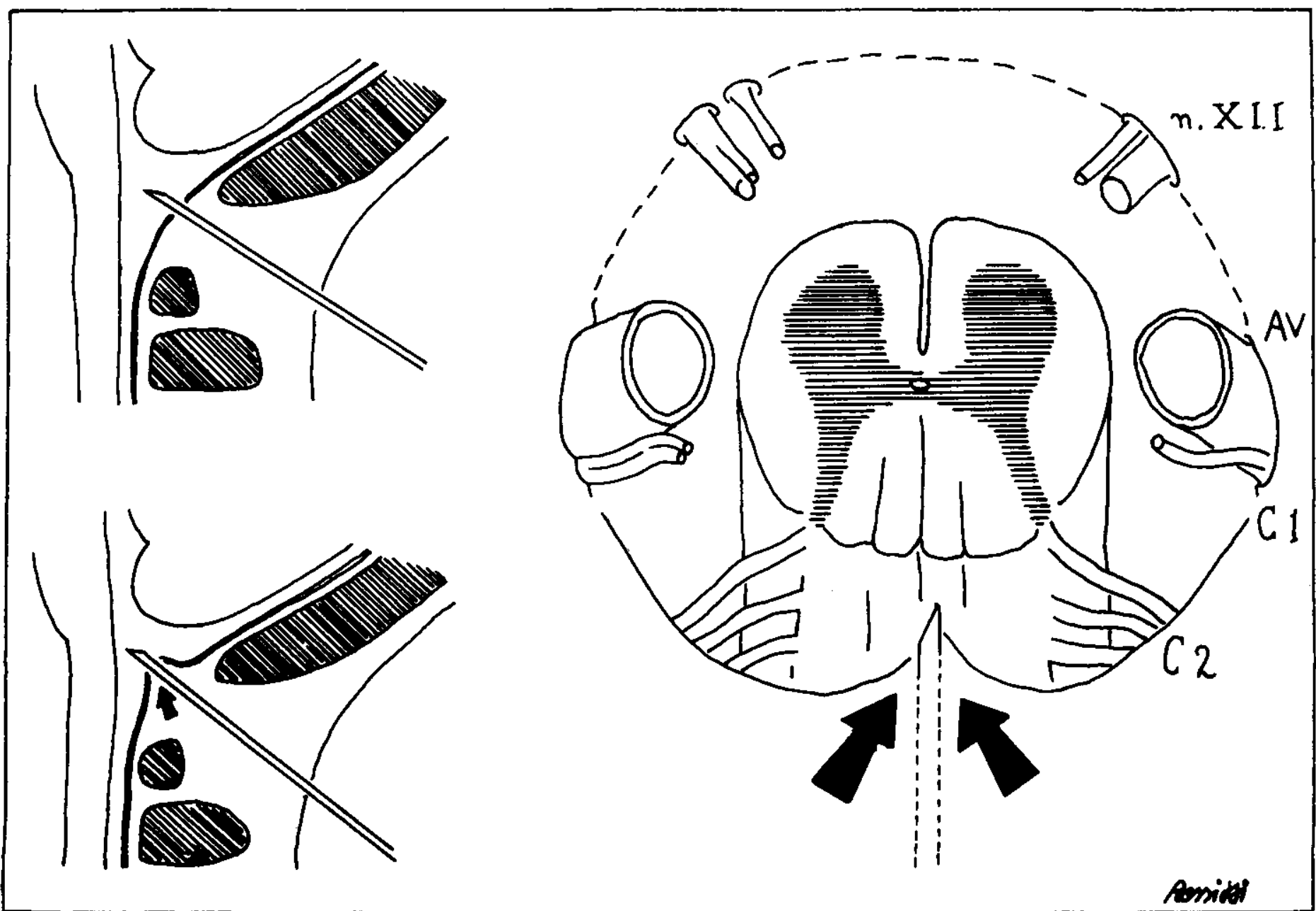

Fig. 1 - Diagrama da PSOM. À esquerda, acima: representaçâo estatica, sem nenhuma distorcão da DM, conforme apresentado na maioria dos livros-texto. A esquerda, abaixo: representaça dinamica, mostrando o deslocamento dia DM. A direita: representacão semi-esquematica da PSOM observada do compartimento intracraniano (vide «Material $e$ Métodos»); observe-se o deslocamento em «tenda» da DM (setas) à penetnação da agulha. AV, artéria vertebral-segmento $V_{4} ; n$. XII, $n$. hipoglosso; $C 1, C 2$, raizes espinhais correspondentes.

Fig. 1 - Diagrama da PSOM. À esquerda, lacima: representação estática, sem nenhuma distorção da DM, conforme apresentado na maioria dos livros-texto. $\tilde{A}$ esquerda, abaixo: representação dinâmica, mostrando o deslocamento da DM. $\tilde{A}$ direita: representação semi-esquemdtica da PSOM observada do compartimento intracraniano (vide «Material e Métodos»); observe-se o deslocamento em «tenda» da DM (setas) à penetração da agulha. AV, artéria vertebral-segmento V4; $n$. XII, n. hipoglosso; Cl, C2, raizes espinhais correspondentes. COMENTÁRIOS

A cisterna magna cerebelomedular (CM) situa-se entre a face caudal do cerebelo (região póstero-inferior do vermis na porção mediana e, de cada lado, a tonsila cerebelar, cujo pólo é percorrido pelo segmento medular lateral da PICA) e a face 
dorsal da medula oblonga. Comunica-se com o $\mathrm{IV}^{9}$ ventrículo por suas aberturas laterais e mediana. Continua-se anterolateralmente com a cisterna cerebelomedular lateral e, inferiormente, com o espaço subaracnóideo espinhal. Sua porção mediana, dorsocranial, é de morfologia muito variável, continuando-se com a cisterna vermiana superior e cisterna hemisférica do cerebelo ${ }^{2}$. Os estudos anatômicos de Lang 2, muito precisos, estabelecem que a CM mede de 30 a $35 \mathrm{~mm}$ em sua maior extensão laterolateral e, em média, $15 \mathrm{~mm}$ em sua maior profundidade dorsoventral. Essas medidas, estáticas, nem sempre correspondem à situação real, como veremos a seguir.

O forame magno do adulto mede $35,33(30,0-41,4) \mathrm{mm}$ em sua extensão sagital, e 29,67 (21,3-37,6)mm em sua extensão frontal ${ }^{4}$. Aqui, a espessura da DM é de 0,5 a $0,6 \mathrm{~mm}$ em sua face dorsal e de 0,3 a $04 \mathrm{~mm}$ na face ventral ${ }^{3}$. A medula espinhal em seu segmento $\mathrm{Cl}$ mede $10,38 \quad(11,0-7,0) \mathrm{mm}$ em seu diâmetro sagital e 12,6 $(16,0-11,0) \mathrm{mm}$ em seu diâmetro frontal, este alargando-se superiormente até 18 (22-16)mm ao nível das olivas bulbares 3. A transição bulbomedular encontra-se relativamente fixa ao nível do forame magno, suspensa por um sistema de ligamentos pia-aracnóideos: ligamento denteado, septum posticum e laço rombóideo L 3. A despeito desse sistema de sustentação, a medula espinhal desloca-se de acordo com a posição e movimentos do corpo: a magnitude do movimento anteroposterior no segmento cervical pode chegar a $9 \mathrm{~mm}$, sendo ao nível do atlas de $3,1 \mathrm{~mm}$ em mediai; a mobilidade laterolateral é máxima no cone medular (de 12 a 18mm) e mínima no forame magno, em média de $5 \mathrm{~mm}$ segundo Molinowsky (1910) citado por Jirouti; quando a cabeça é fletida anteriormente, a medula espinhal ascende de 18 a $28 \mathrm{~mm}$, medida em sua superfície dorsal, segundo Breig (1960) citado por Lang 3.

O deslocamento da DM na PSOM foi verificado por Ward e col. 7, com método semelhante ao nosso, complementado por radiologia. Esse estudo, porém, limita-se a advertir sobre a diminuição da distância entre a DM e o bulbo pela «tenda durai» durante a PSOM, omitindo mensurações mais precisas desse deslocamento.

Em suma, o deslocamento da DM na PSOM, em média de 3,12mm em nossas observações, parece não representar risco maior para esse procedimento, respeitadas suas indicações e realizado com técnica cuidadosa. $O$ presente estudo complementa nossas observações anteriores sobre a anatomia dinâmica das punções cisternais e suas implicações clínicas 5,6.

Agradecimento - Ao Prof. Dr. Sílvio dos Santos Carvalhal e ao Departamento de Anatomia Patológica da FCM-PUCCAMP, pela colaboração neste estudo.

\section{REFERÊ N C I A S}

1. Jirout J. Pneumomyelography. Springfield: Charles C. Thomas, 1969.

2. Lang J. Die äusseren Liquorräume des Gehirns. Acta Anat (Basel) 1973, 86:267.

3. Lang J. Craniocervical region, central nervous system and envelopes. Neuro-Orthopedics 1986, $2: 1$.

4. Lang J, Schafhauser O, Hoffmann S. Ueber die postnatale Entwiklung der basalen Schädelpforten: Canalis caroticus, Foramen jugulare, Canalis hypoglossalis, Canalis condi- $\neg$ laris und Foramen magnum. Anat Anz (Jena) 1983, 153:315.

5. Rossitti SL, Araújo JFM, Sperlescu A, Balbo RJ. Observações sobre o deslocamento da dura-máter nas punções cisternais laterais. Arq Neuro-Psiquiat (São Paulo) 1990, 48 : 469.

6. Rossitti SL, Balbo RJ. Sinal de Lhermitte durante punção cervical lateral: sumário dos acidentes possíveis na punção lateral $\mathrm{C} 1-\mathrm{C} 2$ e relato de dois casos de penetração medular. Arq Neuro-Psiquiat (São Paulo) 1990, 48:341.

7. Ward E, Orrison WW, Watridge CB. Anatomic evaluation of cisternal puncture. Neurosurgery 1989, $25: 412$. 